\title{
RECENT TRENDS IN IMIMUNOLOGY AND VACCINATION AGAINST NEWCASTLE DISEASE VIRUS
}

\author{
Sana Shakoor, Sania Naeem, Ramsha, Naila Shahid, Abdul Qayyum Rao* and Ahmad Ali Shahid \\ Centre of Excellence in Molecular Biology, University of the Punjab, 87-West Canal Bank Road, Lahore-537oo, Pakistan \\ *Corresponding author: qayyumabdul77@yahoo.com
}

\section{INTRODUCTION}

Poultry is one of the largest groups of livestock all over the world. Newcastle disease (ND) is an infectious, contagious, septicemic, fatal and destructive poultry disease that primarily affects chicken and turkey. This disease is responsible for huge economic losses to the global poultry industry. It has also devastating effect on the domestic poultry production. This viral disease was first time appeared in 1926, in England (Newcastle). This disease is now found all over the world, causing symptoms such as nervous manifestation, diarrhea and acute respiratory disease. Newcastle Disease Virus (NDV), the causative agent of ND, belongs to the Paramyxoviridae, which is a large family of RNA viruses having envelope and negative strand of RNA. The virus envelope is lipid in nature and derived from plasma membrane of host cell (Lamb and Jardetzky 2007).

Traditional vaccines and variety of diagnostic tests are available for prevention and diagnosis of NDV, respectively. Traditional vaccines are still used, but they have been linked to disease symptoms and failure to respond under field conditions. To address the issues with conventional vaccines, recombinant vaccines have been developed by expressing various immunogenic genes.

\section{Newcastle Disease}

ND is an infectious disease of birds that can be transmitted to humans. It is a disease that affects both domestic and wild avian species. It is highly contagious viral infection that affects poultry and birds of all ages and both sexes. The most susceptible avian species of ND are: chickens, pigeons, Japanese quails, turkeys, guinea fowls, ducks and other wild birds irrespective of their ages. Some mammals, including dogs, cats and humans, are also susceptible to ND (Ashraf and Shah 2014). Since 66\% of the population in developing countries lacks access to a proper protein diet, ND is considered as vital in the poultry industry in these countries, as it poses a significant economic threat to the industry and causes huge losses in poultry all over the world (Abdisa and Tagesu 2017).

\section{History}

Although the ND panzootics occurred in all over the world but specifically epizootics have been reported in Africa, Asia, South and Central America and sporadic epizootic have occurred mostly in Europe. The very first panzootic was reported from 1926 to late 1950s in Newcastle-upon-Tyne (England) from Europe, as well as Java (Indonesia) from Southeast Asia (Seal et al. 1995; Qiu et al. 2011). In 2012, APMV type I serotype caused the serious disease in birds of Jallo Wildlife Park in Lahore, Pakistan, resulting in the deaths of 190 peacocks. Overall, it resulted in a $100 \%$ mortality rate, as well as $50 \%$ damage to the susceptible birds. After isolating the causative agent and conducting various serological and molecular diagnostic investigations, such as PCR, ELISA, and the HI test, the velogenic strain NDV was verified. Different strains of NDV have different rates of morbidity and mortality in birds (Shahzad et al. 2015; Abdisa and Tagesu 2017).

\section{Importance of Poultry}

Poultry is the most common domestic animal stock in the world in terms of animal numbers. In the backyard animal production of developing countries, poultry occupies very important position. Poultry is a source of income for villagers in developing countries. Backyard poultry production poses a high risk of infection, such as ND in poultry, due to fewer biosecurity activities. Poultry serve as inexpensive and a high-quality source of protein in the developing countries. Availability of eggs is approximately increasing up to $4 \%$ each year (Thomazelli et al. 2012). According to a Pakistani survey, there are approximately 1105.91 million poultry birds in the country, with approximately $\mathbf{1 5 2 . 4 4}$ million rural poultry. Poultry provides a significant contribution to the village's economy, accounting for 3611 million eggs and 100.42 metric tons of total poultry meat (Khan et al. 2010).

\section{Newcastle Disease Virus}

\section{Epidemiology}

The most destructive NDV panzootics have occurred over the last ten decades. The first one began in Asia and Europe and spread across the world over the course of 20 years, beginning in the mid-1920s. The second pandemic spread to the entire world in just four years due to the commercialization of the poultry industry and increased foreign exchange in cage birds, which served as a source of NDV. The third pandemic, during 198os, in the racing pigeons was believed to be caused by genotype VI isolates. This pandemic also showed wreaking havoc on a variety of 
birds uncontrollably due to excessive racing pigeon's husbandry (Meng et al. 2016). Similarly, fourth pandemic, which spread in late 1980s, also caused huge economic losses to a vast number of countries, including Middle East, Africa, Europe, and South East Asia. The fourth pandemic is thought to be caused by NDV genotype VII, which is the fastest-evolving strain of the virus. The emergence of virulent NDV strain has always posed to the poultry industry. Major source of reservoir for the emergence of virulent strain is the lentogenic strain. In term of ecological interference, this strain can be easily transmitted form wild birds to domesticated poultry. The emergence of virulent NDV strains has always posed a risk to the poultry industry. Lentogenic strains are a major reservoir for the emergence of virulent strains. In terms of environmental impact, this strain can easily be transmitted from wild birds to domesticated poultry (Ayala et al. 2016).

\section{Structure}

Newcastle diseases virus (NDV) is the causative agent of Newcastle Disease. This is a non-segmented, single stranded, RNA virus. It belongs to Avian Paramyxovirus (APM) type I, genus Avula Virus, family Paramyxoviridae (Fauquet and Fargette 2005). A wide range of both domestic and wild birds can be affected by NDV. The genome of NDV consists of six genes, named as nucleocapsid (NP), phosphoprotein $(\mathrm{P})$, matrix protein (M), fusion protein (F), large protein (L) and hemagglutinin-neuraminidase protein $(\mathrm{HN})$. All the viral genes are monocistronic; forming a single structural protein, except the $\mathrm{P}$ gene. $\mathrm{P}$ gene is transcribed to give three mRNA encoding, two nonstructural (W and V) and one structural (P) protein (Yusoff and Tan 2001). Virus
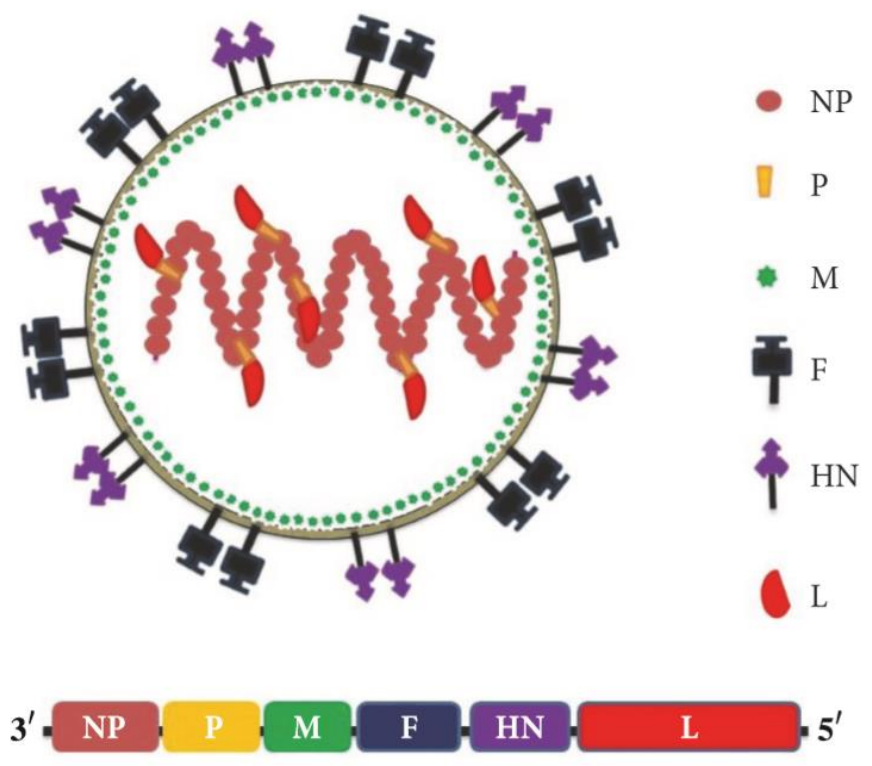

Fig. 1: Structural feature of New Castle Disease Virus. Figure displaying morphology of virus showing all the associated proteins. NP, P and L linked with RNA Genome. M. F and HN attached with envelop (Ganar et al. 2014).
(Yusoff and Tan 2001). Virus transcription and replication are regulated by the 3' and 5' ends of the viral genome, which accommodate the regulatory signal (Conzelmann 2004). NDV appears to be polymorphic with spike projection if glycoproteins from the surface of enveloped particle; that initiate the virus infection cycle. M protein is just beneath the viral envelope, maintains shape of virus and assists in packaging and release of virus (Fig. 1). Therefore, viral genome, associated with these three proteins, is responsible for replication related function. $\mathrm{L}$ protein serves as transcriptase and replicase during infectious cycle, with the $\mathrm{P}$ protein acting as a cofactor (Steward et al. 1993).

The severity of illness in birds ranges from subclinical symptoms to $100 \%$ mortality. On the outside of the envelope of virus, both of these proteins form the protrusions and act as the neutralizing, as well as protective, proteins of NDV. The F protein is produced in the form of inactive form or precursor called $\mathrm{F}_{\mathrm{o}}$. Proteases from host cells cleave this inactive form into two subunits called $F_{1}$ and $F_{2}$; both are biologically active subunits. This cleavage of inactive form is precondition and essential requirement for the viral entry and fusion with cells. The sequence of the chief element of pathogenicity, that is $\mathrm{F}$ protein cleavage site, is a well characterized. To initiate the process of fusion, homotypic interaction between the $\mathrm{F}$ and $\mathrm{HN}$ proteins is required (Kim et al. 2013).

\section{Categories}

Due to great variation in the severity of disease, NDV was not identified as only one clinico-pathologic identity; it is categorized into 4 pathotypes. These pathotypes are; Doyle, Beach, Beaudette, and Hitchner. But recently, the NDV has been categorized on the basis of pathogenicity of the disease from most to least pathogenic (Kammon et al. 2015). These categories are: (i) viscerotropic velogenic (ii) velogenic (iii) mesogenic and (iv) lentogenic.

Among these strains, velogenic strains are considered extremely lethal, with a $100 \%$ mortality rate. These strains cause lesions that have adverse effects on digestive system, respiratory system and even the nervous system. The velogenic strain has further 2 sub-categories, depending on the organ affected. These sub-categories are: (a) viscerotropic and (b) neurotropic. Viscerotropic was formerly called as Doyle and specifically affects the visceral organs of birds. The neurotropic was formerly called as Beach and symptoms caused by this strain are associated with nervous system. After the velogenic strains, the mesogenic strains possess intermediate virulence that causes proven disease in chickens, characterized by intermediate effects on nervous and respiratory systems. The mortality rate of mesogenic strains is low. The lentogenic strains include the members like Ulster strains, LaSota and $\mathrm{V}_{4}$; these strains generally are not associated with remarkable clinical illness in mature and grown-up chickens or birds. These strains are used for the production of live vaccines (Abdolmaleki et al. 2018). 
All strains of NDV belong to a single serotype but all these strains are identified or recognized even by the slight antigenic and genetic variation. The study of successive years on the recognition of various increasing changes in the NDV strains proved that the virus is constantly evolving. Depending upon the sequence of $\mathrm{F}$ gene and genome size, all strains of NDV are classified into two classes, class I and class II. Class I has 9 genotypes, while class II has eleven genotypes. Strains in class I are generally avirulent. But in one recent study it is reported that there is only a single genotype and 15 groups on the genetic basis in class I and class II, respectively. Class II has both types of strains that is virulent and avirulent and includes the previously identified 10 genetic groups and five new genetic groups. Avirulent strains, like LaSota and $\mathrm{B} 1$ of class II, are consider as avirulent vaccine strains. It is reported that V, VI and VII genetic groups of class II are associated with the outbreaks of the disease in the whole world (Khan et al. 2010; Kammon et al. 2015).

\section{Clinical manifestations of Newcastle disease}

The symptoms of ND vary, depending on the strains of causative agent. Some strains are asymptomatic, while other cause disease with $100 \%$ mortality rate. Clinical manifestation of ND has involvement of gastrointestinal tract, respiratory tract, as well as nervous system, causing ruffled feathers, conjunctivitis, diarrhea, paralysis, dyspnea, prostration, nasal discharge and tremors. Ulcers and haemorrhages in the various regions of digestive tract, as well as patches showing necrosis, have been observed in GALT, liver and spleen through internal examination (Siddiqui et al. 2014). All four types of NDV strains show different but closely related clinical signs (Abdisa and Tagesu 2017).

In viscerotropic velogenic ND, remarkable lesions, depression, profused greenish yellow diarrhea, swollen heads, decreased egg production, and cyanotic combs can be seen in infected animals. Mortality rate is $90 \%$. Neuroptopic velogenic strain shows acute symptoms of nervous system and respiratory tract. All signs appear suddenly and simultaneously. Mortality rate is around 10$20 \%$ in adult fowls, while higher in young birds. In case of mesogenic pathotype, clinical symptoms from respiratory tract with coughing dominate, while depression, decreased egg production and weight loss can also be observed. Mortality rate is approximately $10 \%$. Lentogenic pathotype shows mild signs of respiratory tract and a very small drop in egg production. Mortality is very low, and may be negligible.

Onset of ND is rapid, and its signs appear as the aerosol exposure take places within 2 to 12 days, throughout the flock. When the virus is transmitted through fecal-oral route in caged birds, the spread rate is slower. Eggs from infected birds are usually abnormal in shape, color, surface and having watery albumen. Ataxia, body or head tremors and torticollis develop in poorly vaccinated fowls within 10 to 14 days. A well vaccinated bird may not show any symptoms of infection, except decreased egg production and shedding of virus in feces and saliva.
Severity of the disease depends on the tropism and virulence of virus, susceptibility of the host species, age of bird, immune status, environmental conditions, and presence of other diseases.

Besides avian species, humans can also be affected by the NDV (MacLachlan and Dubovi 2017). On the exposure of virus, conjunctivitis is caused in humans. The conjunctivitis recovers quickly after 4-7 days of infection, but the causative agent tends to be shed in the ocular fluid. In case of mild infection, the disease appears as influenza with symptoms of headache and fever. Laboratory persons and vaccinators are at the great risk of disease. Risk can be reduced in the laboratory persons by using personal protective equipment (PPEs) and safety cabinet. The disease rarely occurs in farm workers and consumers of poultry products. It has been reported in previous studies that NDV can easily transmit from birds to human and vice versa but not from human to human (Abdisa and Tagesu 2017).

\section{Diagnostic tests of NDV}

Proper diagnosis of a causative agent is crucial for successful cure of any disease. Clinical signs and symptoms always give clue to the medical personnel to diagnose that disease, which then can further be confirmed through other diagnostic tools to better combat the disease. It is critical to quickly identify the NDV strain and distinguish it from other closely related pathogenic strains, so that the virus can be controlled. The diagnostic tests of NDV are based on clinical symptoms, serological testing, conventional and molecular based assays, microarray techniques and next generation sequencing (Table 1).

\section{Conventional assays}

NDV is initially diagnosed on the basis of clinical features that distinguish the NDV from other viruses and one strain of NDV from another strain. All pathotypes show different but closely related symptoms i.e, depression, diarrhea, tremors, paralysis, decreased egg production and have different severity and mortality rates (Marks et al. 2014). Then the virus samples are isolated from the sites of replication, viral shedding, and routes of transmission. The samples may be oropharyngeal and cloacal swabs in live birds. In case of recently died animals, the samples may be taken from liver, kidneys, spleen, caecal tonsils, lungs or intestine (OIE 2017). After that, hemagglutinin (HA) and hemagglutinin (HI) tests are performed to confirm the presence of virus in infected cavity fluid. It is advisable to perform virus isolation both in allantoic cavity and cell cultures (Bello et al. 2018). Enzyme linked immunosorbent assay technique (ELISA) is another test used to detect antibodies against all pathotypes of NDV. It is possible to develop ELISA that can distinguish between infection antibodies and vaccine antibodies (Ge et al. 2016). It can also eliminate the cross reactivity of NDV with other paramyxoviruses, using $C$ terminal extension NP recombinant protein as a detecting antigen (Zhao et 
al. 2018). Virus neutralization test is another serological test to measure NDV specific neutralizing antibody.

\section{Molecular based assays}

The conventional techniques are found to be relatively slow and expensive. In order to overcome these shortcomings, molecular based accurate NDV detection methods have been developed. Among these molecular techniques, RT PCR is commonly used assay in developing countries. A wide range of PCR protocols (from conventional RT-PCR to real time RT-PCR) have been used. These are sensitive and rapid diagnostic techniques. Singleplex and multiplex real time RT PCR have also been used for rapid detection of viruses. Triplex real time PCR has been found to have 10 times more detection limits for $\mathrm{NDV}$, avian influenza and duck tembusu virus (Zhang et al. 2020). qPCR is also a molecular assay which gives greater detection sensitivity of specific viral disease. Another non-PCR amplification technique is used for rapid diagnosis of pathogens. It works on the principle of strand displacement reaction in which a stem looped structure is formed allowing the rapid and sensitive amplification of target gene.

Microarray hybridization technique is used to diagnose avian influenza and NDV simultaneously in a mixed infection sample (Lung et al. 2012). In recent years, multiplex Luminex suspension microarray system has been used for rapid detection of NDV (Sultankulova et al. 2017). Most recently, different researches on the use of microarray have been carried out which showed it as the most reliable and promising technique for diagnosis of NDV (Xiao et al. 2019). Biosensors are another emerging diagnostic tool of $21^{\text {st }}$ century, which gives incredibly inexpensive, effective, sensitive and rapid results of pathotype. These are made up of transducers (physicochemical detectors) and biorecognition molecules, which can convert biomolecular interactions in the measurable signals. In recent years, a label free immunosensing scheme, having tilted fiber grating equipped with gold nanospheres, has been developed. This system is more sensitive than qPCR (Luo et al. 2018; Mauriz 2020).

Table 1: Diagnostic tools for the detection of NDV

\begin{tabular}{|c|c|c|c|c|}
\hline $\begin{array}{l}\text { Diagnostic } \\
\text { techniques } \\
\end{array}$ & Basis & Advantages & Limitations & References \\
\hline \multicolumn{5}{|l|}{ Conventional Assays } \\
\hline $\begin{array}{l}\text { Differential } \\
\text { diagnosis }\end{array}$ & - Clinical symptoms & -Easy to perform & $\begin{array}{l}\text { - Similar symptoms with other } \\
\text { paramyxoviruses } \\
\text { - Cause confusion in treatment }\end{array}$ & (Bello et al. 2018) \\
\hline Virus isolation & $\begin{array}{l}\text { - Used swabs for sampling } \\
\text { - HA and HI tests for confirmation } \\
\text { - Cynctia formation }\end{array}$ & - Definitive method & - Not reliable & (Alexander 2000) \\
\hline Serological Assays & $\begin{array}{l}\text {-Antigen antibody serum detection } \\
\text { - ELISA } \\
\text { - VNTs }\end{array}$ & $\begin{array}{l}\text { - Important for } \\
\text { humoral immune } \\
\text { responses }\end{array}$ & $\begin{array}{l}\text {-Expensive } \\
\text { - Cannot identify } \\
\text { distinguished strains }\end{array}$ & (Choi et al. 2013) \\
\hline \multicolumn{5}{|l|}{$\begin{array}{l}\text { Molecular based } \\
\text { assays }\end{array}$} \\
\hline RT-PCR & -Target F gene & - Sensitive and rapid & $\begin{array}{l}\text { - Cause mutation in primer } \\
\text { binding region } \\
\text { - Dire need to improve } \\
\text { primers according to } \\
\text { evolution }\end{array}$ & (Wang et al. 2001) \\
\hline Real Time RT-PCR & $\begin{array}{l}\text {-TaqMan probes are used to target F } \\
\text { gene } \\
\text { - Singleplex and multiplex RT PCRs }\end{array}$ & $\begin{array}{l}\text {-More sensitive and } \\
\text { rapid } \\
\text { - Non cross reactive }\end{array}$ & -Need proper expertise & (Zhang et al. 2020) \\
\hline qPCR & $\begin{array}{l}\text { - Target Fusion }(\mathrm{F}) \text { and matrix gene } \\
\text { - Improved method known as } \\
\text { matrix polymerase multiplex-qPCR }\end{array}$ & $\begin{array}{l}\text { - Less tiring } \\
\text { - Reliable } \\
\text { - Faster } \\
\text { - Greater sensitivity }\end{array}$ & - Detect only class II NDV & (Miller et al. 2010) \\
\hline $\begin{array}{l}\text { No- PCR } \\
\text { amplification }\end{array}$ & $\begin{array}{l}\text { - LAMP test } \\
\text { - Detect } 6 \text { independent regions } \\
\text { - SYBR green is used for visualization }\end{array}$ & $\begin{array}{l}\text { - Inexpensive } \\
\text { - Sensitive and rapid }\end{array}$ & $\begin{array}{l}\text { - Different primers for } \\
\text { different independent sites }\end{array}$ & (Pham et al. 2005) \\
\hline $\begin{array}{l}\text { Microarray } \\
\text { hybridization } \\
\text { technique }\end{array}$ & -Various DNA probes are used & $\begin{array}{l}\text { - Efficient for } \\
\text { genotyping and } \\
\text { phenotyping } \\
\text { - Reliable }\end{array}$ & - Need expertise & (Lung et al. 2012) \\
\hline Biosensors & $\begin{array}{l}\text { - Used detectors and biorecognition } \\
\text { molecules }\end{array}$ & - Rapid and effective & -Sensitive to $\mathrm{pH}$ & (Shi et al. 2015) \\
\hline NGS & $\begin{array}{l}\text { - Differentiate virulent from } \\
\text { avirulent strains }\end{array}$ & $\begin{array}{l}\text { - Promising tool } \\
\text { Accurate and reliable }\end{array}$ & -Expensive & $\begin{array}{l}\text { (Deurenberg et al. } \\
\text { 2017; Chen et al. } \\
\text { 2020) }\end{array}$ \\
\hline $\begin{array}{l}\text { Random priming } \\
\text { technology }\end{array}$ & $\begin{array}{l}\text {-Random amplification of gRNA } \\
\text { and sequence analysis }\end{array}$ & $\begin{array}{l}\text { - Detect virus at very } \\
\text { low concentration }\end{array}$ & - Expensive & $\begin{array}{l}\text { (Byarugaba et al. } \\
\text { 2014) }\end{array}$ \\
\hline
\end{tabular}


Next generation sequencing is the most recent technology used for rapid and most reliable diagnosis of NDV. It can detect mixed infection within the same host and low frequency variants. Recently, genotype VI of NDV has shown continuous evolution in NDV genome (He et al. 2018). Various researches have been done on studying NGS technology for the diagnosis of NDV genes (P-gene), which showed that NGS is an excellent, revolutionizing technology used for this purpose (Chen et al. 2020).

\section{Vaccines against NDV}

Development of vaccines against NDV is a major concern. Vaccines that are presently in use are a few decades old. In USA, live vaccines were started in 1945. Live vaccines and inactive vaccines were available from 1950 to 1990 . During that time, researchers investigated the development of symptoms after the vaccination using live vaccines. The problems related to live vaccines became clear in 2016 (Dimitrov et al. 2017). The major problems related to live and inactivated vaccines are: (i) high dose of live vaccines elevate the cost, (ii) live vaccines are able to reduce the symptoms but unable to stop the replication of NDV and, (iii) the inactivated vaccines are not very effective (Dimitrov et al. 2017). To overcome these problems, the recent trend is set to develop the recombinant vaccines. Recently, plant based Edible vaccine, a type of recombinant vaccine, which can be fed to animals orally to induce immune response, has also gained attention of scientists. In different studies, transgenic potato plant, tobacco root hair, maize and yeast have been reported for the expression of $\mathrm{HN}$ and $\mathrm{F}$ proteins of NDV.

The two major categories of vaccines are: i) conventional vaccine which is an old vaccine technology and, ii) recombinant vaccines used as recent technology to prevent NDV in poultry animals (Table 2 ).

\section{Status and consideration of vaccine development}

A number of studies on NDV control strategies in poultry industry have been conducted. Different vaccines have been developed for preventing the occurrence of disease and saving the poultry birds for food security. Previously, live inactivated vaccines (Inactivated Chick-ND Hester) and attenuated vaccines (LaSota) were available in the market and licensed in many countries to control the spread of disease. These vaccination techniques do not offer sterilizing immunity and fail to make the flocks highly resistant to natural viruses. However, the main strategy is to vaccinate the fowls with live lentogenic strains at two to four weeks or day-old birds, which should be revaccinated at 2-4 weeks and again at tenth week with an inactivated mesogenic or lentogenic strain. Vaccine delivery through aerosol or water drinking method has found to be convenient and effective but still due to varying uptake rate and stocking densities, the success rates have been reduced to 53 and 6o\% through these methods, respectively. Live vaccines may mask the clinical signs when the NDV infection occurs in vaccinated animals, but these are inexpensive and can be directed on large scale to produce mucosal immunity. Vaccination of the flocks depend on the national and international policies under the regulations of OIE. In many European countries, emergency and prophylactic vaccines are in use. Vaccination strategies are routinely used in developing countries where NDV is endemic. Booster vaccines of the live mesogenic pathotype are used to improve immunogenic responses, but their use is still illegal in many countries (Mayers et al. 2017). Currently, with the emergence of molecular biology and recombinant DNA technology, new vaccine strategies named as recombinant vaccines have been developed to prevent the disease and protect the birds from virus.

While designing a vaccine for poultry flocks, various factors should be considered to avoid adverse reactions and to protect birds from infection; these factors include maternal antibodies level, age, breed of the fowl and other infections which can weak the immune system of animals. Vaccine should be cost-effective, easy to store and appropriate for mass administration. There is a dire need to improve control strategies through enhanced biosecurity practices and good vaccination protocols to cut down the burden of NDV on poultry industry in developing countries.

\section{Old vaccination strategies}

Old vaccination strategies include conventional vaccines, which are either live attenuated vaccines or inactivated vaccines.

\section{Live Attenuated Vaccines}

NDV has been decreased in many countries due to the isolation of naturally occurring immunogenic strains of NDV. A number of strains, like B1, F, LaSota, $V_{4}$ and I2, among the lentogenic category of NDV have been used as live vaccine for disease control (Commission and Committee 2008). LaSota is the most widely used vaccine strain due to its high immunogenicity. B1 strain is less immunogenic than the LaSota strain but it is also widely used for vaccine purpose due to its quality of being highly attenuated and lack of respiratory reactions in birds after vaccination. The advantage of $\mathrm{V}_{4}$ and $\mathrm{I}_{2}$ is their thermostability, which makes them suitable for villages with limited refrigeration capacity (Bensink and Spradbrow 1999). Other NDV strains, like Komoroy and Mukteswar, were used as booster vaccines following the administration of the lentogenic strain. All these live attenuated vaccines are highly effective because they stimulate both systematic and mucosal response like that of natural response, because of their ability to replicate in chicken. Furthermore, a single dose of live NDV vaccine stimulates enough immune response to protect against clinical disease but does not stop the shedding of virulent virus by oropharyngeal and cloacal routes. Studies have shown that this shedding can be reduced when increased doses of live vaccines are administered. Due to the high cost of vaccine per bird, this method is not proved to be economically acceptable, therefore, improved and cost- 
effective approach is requited to overcome the problem of virus shedding. Tissue tropism is the most important factor in determining the effectiveness of a vaccine. Among the conventional vaccines, the most famous strain is the LaSota strain, which provides strongest immunity along the path where initial exposure to virus may occur. Other than this, VGGA strain was proved to be enterotropic, stimulating mucosal immunity. The greatest advantage of live NDV vaccines is their ease of mass application in water or even in spray, which makes them highly cost effective and manageable. In addition, the concept of herd immunity is also studied under the administration of live vaccines (Dimitrov et al. 2017).

Nevertheless, despite their variety and advantages, these vaccines have certain shortcomings. The first and foremost disadvantage is that live vaccines have the potential to revert to virulent form, inducing the disease again. Secondly, different strains may cause different post vaccination respiratory infections. Another major problem is that vaccines are mostly based on genotype I and II, which are different from present day genotypes in many countries. Although a vaccine protects against clinical disease, but these factors could be very dangerous. Therefore, the live attenuated vaccines must be used with extreme caution and care, and a well improved vaccine is needed to overcome the weaknesses of conventional live attenuated vaccines.

\section{Inactivated vaccines}

Chicken immunization with inactivated vaccine is the earliest strategy of controlling NDV. The vaccine is produced by growing desired strain of NDV, followed by inactivation using chemical and physical methods. The method of inactivation should be able to separate the immunogenic epitopes of viral surface glycoprotein (HN and F), which are the most crucial determinants of neutralizing antibody. Widely used chemicals for inactivation are binary ethylenimine (BIE) and formaldehyde. The vaccine is administered subcutaneously or intramuscular, after being prepared in emulsion of mineral oil. These vaccines cannot be administered in masses but have to be given individually via parenteral route because these viruses do replicate and spread horizontally. As a result, the entire procedure is costly and time-consuming (Kapczynsk et al. 2013). Moreover, a great deal of care is needed during inactivation process of the virus, as too much inactivation may destroy immunogenic epitopes, while less exposure to chemicals may not completely inactivate the virus. To improve the efficacy of vaccines, they are primed with live vaccines before administration and also require use of adjuvants to trigger immune response. Besides, these adjuvants may cause some unwanted reaction in birds. In addition, inactivated vaccines are known to be bad inducers of mucosal immunity. Thus, to ensure better protection and care, a rationally designed vaccine with improved characteristics is required in the poultry industry (Zhai et al. 2011).

\section{New vaccine technologies}

\section{Recombinant vaccines}

Currently, recombinant vaccines are used as an alternative to conventional vaccines to overcome their limitations. Some of the recombinant vaccines are as follows:

\section{DNA vaccines}

The advancements in recombinant DNA technology, paved the way of developing recombinant DNA vaccines through cloning process. In this process, the gene encoding of different neutralizing epitopes or an immunogen is cloned into an expression vector. Then the cloned vector is injected into the fowl host, where the transgene is transcribed and translated into protein, acting as epitope which induces immune response (Bello et al. 2018). F and $H N$ gene cloned vectors are used to vaccinate chickens, which then are boosted through inactivated vaccines, as a result, a very strong response is observed. It has been noticed that recombinant DNA vaccines can be used to boost the immune response induced through inactivated vaccines. These can be improved further by using nanoparticles as a vehicle to deliver a vaccine (Firouzamandi et al. 2016).

In recent years, $\mathrm{F}$ gene-based DNA prime protein vaccine strategy has been experienced and its results showed that DNA prime protein boost technique can easily boost up the immune response in poultry birds. This approach gave 91.6\% protection from NDV and showed higher immunity level than DNA vaccines (Khulape et al. 2019). These are safer alternatives against ND vaccination challenges and more capable of inducing both humoral and cell mediated (CD4+ and CD8+) immune responses. Still, they have some limitations, including high cost, poor immunogenicity, and difficult mass delivery system. These limitations can be overcome by using suitable adjuvants (Zhao et al. 2017).

\section{Nanoparticle vaccines}

Recent advances in nanotechnology have made vaccine delivery much easier. Nanoparticles are used as delivery vehicles, which protect the delivered antigen from external disruption. This process is beneficial in controlled release of immunogen; it also enhances the duration of immune response. Various types of nanomaterials are used as carriers such as chitosan, polylactic acid, magnesium sulphate, carboxymethyl-cellulose and calcium phosphate. It has been seen in a study that two chitosan used as delivery vehicles can enhance humoral, mucosal and cell mediated responses (Renu and Renukaradhya 2020).

\section{Viral Vector Vaccines}

Recombinant viral vector vaccine strategy is the most promising approach to control infectious diseases. In poultry, most used vectors are vaccinia virus, herpes virus 
and fowl pox virus because of their large dsDNA genome, which enhance their capacity of transgene expression. These are most effective vaccines but still have challenges to their performance due to the presence of maternally derived antibodies in neonatal chicks (Baron et al. 2018). In fowl pox virus vaccine, thymidine kinase is replaced with $\mathrm{HN}$ or $\mathrm{F}$ or both genes, and showed high level of immunity against NDV. Although there are no postvaccinal reactions in fowl pox vectors, anti-fowl pox antibodies may interfere with its reactivity, due to which it is not suitable for young birds. This limitation can be overcome by using herpes virus vector, which shows long lasting and strong humoral, and cell mediated immune responses. Herpes vector is an ideal vaccine carrier, which has ability to induce $95-100 \%$ immune response in chicken against NDV. Avian paramyxovirus-3 can also be used as an efficient avirulent vector to induce immune response (Bello et al. 2018). They show high level of immune responses and are highly immunogenic. They can activate TLR and induce strong innate inflammatory immune response. But they still have some challenges, including their sensitivity to preexisted immunity against vectors.

\section{Virus like particles as vaccines}

Virus like particles are composed of outer core only without any genome, have natural configuration of infectious virion and do not have ability of self-replication. Absence of genome makes them effective candidates of vaccines, inducing cell mediated and humoral responses, without the use of any adjuvant. The particulate nature, size and their repetitive structure are important for innate immunogenicity. These are more protective and safer mode of vaccination than conventional vaccines (Liu et al. 2012). NDVLPs have many unique features, including the protein ratio which is similar to wild type NDV and these are released with the efficiency of $84 \%$ (Bello et al. 2018). These are safe to vaccinate and produce robust immune responses. The only limitation is that these cannot be produced in a large amount for massive vaccination.

\section{Reverse genetic based vaccines}

Reverse genetic based vaccine is the latest vaccine used for NDV vaccination; it is the recovery of recombinant virus from cloned cDNA. In reverse genetic based vaccines, the cleavage site of virus is modified from polybasic to monobasic (Kim and Samal 2018). It has been observed in different studies that this approach is superb in making the virus avirulent and inducing significant protective immunity, and reduces the viral shedding when the immunization is achieved. Recently, reverse genetic based vaccine was isolated from naturally recombinant Malaysian strain (NDV IBSo25/13) against NDV genotype VII. In this experiment, pOLTV 5 vector was used to recover virus after modifying their $F$ cleavage site. The results showed that virus was highly attenuated and induced higher level of HI titre (Bello et al. 2020). This approach is pertinent in rapid production of stable attenuated NDV genotype matched vaccines against infectious NDV. These demonstrate the ability to distinguish between virulent and avirulent strains. The disadvantage of this method is the high cost of sequencing and other molecular processes.

\section{Oral Edible Vaccines}

Although already available live attenuated, inactivated, and recombinant vaccines have played an important role in combating NDV but still they show some limitations and challenges, including their high cost, low reactivity, difficulty in massive vaccine delivery and multiple dosage system. To overcome these challenges, plant-based oral edible vaccines have been developed, which provide safer, affordable, and attractive platform for vaccine delivery. In this approach, Agrobacterium mediated gene transfer system or genetically modified plant virus transformation methods are used, through which the desired gene encoding epitopes of specific disease are integrated into plant genome (Laere et al. 2016). Tobacco, potato and maize are most commonly used transgenic plants for the preparation of oral edible vaccines.

In the construction of transgenic potatoes, NDV genes under the control of $35 \mathrm{~S}$ CaMV promoter are incorporated into a binary vector (pGJ357) and transferred to potato through agro-mediated transformation (Berinstein et al. 2005). In another study, gene encoding $\mathrm{HN}$ and $\mathrm{F}$ proteins of NDV, controlled by promoter and terminator as $\mathrm{CaMV}_{35} \mathrm{~S}$ and NOS respectively, were integrated into a plant-based expression vector (pBI121) and transferred to tobacco plant through Agrobacterium tumefaciens mediated transformation. Results showed high immune response in chicken (Ghaffar et al. 2016). Recently, corn has been observed as a successful candidate of inducing immune response in chicken against NDV. In this research, transgenic corn seeds having $\mathrm{F}$ and $\mathrm{HN}$ genes under the regulation of $35 \mathrm{~S}$ and Zein promoters were observed. Results showed approximately 7 and 28 folds higher expressions of $\mathrm{F}$ and $\mathrm{HN}$ genes, respectively. Their analysis showed that chicken fed with these transgenic leaves produced specific antibodies against NDV antigen proteins (Shahid et al. 2020).

\section{Challenges to plant based oral edible vaccines}

Edible vaccines have been used for decades, as they are cost effective, safer, and efficient, but they still have some limitations. Their commercialization and implementation are biggest challenges faced by scientific personnel. Plant based vaccines can also produce hypersensitive responses. Plants need regular monitoring, so that they may not be mixed with non-transgenic plants during pollination or cross-contamination. Quality and safety of GM plants are difficult task to be achieved. These can also contaminate the human food through accidental mixing of plants (Kurup and Thomas 2020). 
Table 2: Vaccines to control NDV

\begin{tabular}{|c|c|c|c|c|}
\hline Vaccine strategy & Process & Pros & Cons & References \\
\hline \multicolumn{5}{|l|}{ Conventional vaccine } \\
\hline $\begin{array}{l}\text { Live attenuated } \\
\text { vaccine }\end{array}$ & $\begin{array}{l}-\mathrm{V}_{4} \text { and } \mathrm{I} 2 \text { thermostable vaccine; } \\
\text { it can bear high temperature }\end{array}$ & $\begin{array}{l}\text {-Mass application in water } \\
\text {-Herd immunity } \\
\text {-Systematic and mucosal response }\end{array}$ & $\begin{array}{l}\text {-Ability to revert back to } \\
\text { virulent form } \\
\text {-Post vaccine infection }\end{array}$ & $\begin{array}{l}\text { (Mielcarek et al. } \\
\text { 2006) }\end{array}$ \\
\hline Inactivated vaccines & $\begin{array}{l}\text {-Physical and chemical damage of } \\
\text { immunogenic viral glycoprotein }\end{array}$ & $\begin{array}{l}\text {-Can administered } \\
\text { subcutaneously and } \\
\text { intramuscularly }\end{array}$ & $\begin{array}{l}\text {-No mass administration } \\
\text {-Expensive and hectic }\end{array}$ & $\begin{array}{l}\text { (Tlaxca et al. } \\
\text { 2015) }\end{array}$ \\
\hline \multicolumn{5}{|l|}{ Recombinant vaccine } \\
\hline DNA vaccines & $\begin{array}{l}\text {-F and } \mathrm{HN} \text { gene cloning into } \\
\text { vector }\end{array}$ & $\begin{array}{l}\text { - Produce both humoral and cell } \\
\text { mediated immune responses }\end{array}$ & $\begin{array}{l}\text { - Expensive } \\
\text { - Poor immunogenicity }\end{array}$ & $\begin{array}{l}\text { (Dimitrov et al. } \\
\text { 2017) }\end{array}$ \\
\hline $\begin{array}{l}\text { Nanoparticle } \\
\text { vaccines }\end{array}$ & $\begin{array}{l}\text { - Nanoparticles used as delivery } \\
\text { vehicles of genes }\end{array}$ & $\begin{array}{l}\text {-Controlled release of immunogen } \\
\text { Enhanced immune responses }\end{array}$ & -Expensive & $\begin{array}{l}\text { (Bello et al. } \\
\text { 2018) }\end{array}$ \\
\hline Viral vector vaccines & $\begin{array}{l}\text { - F and HN genes in Vaccinia, } \\
\text { herpes virus or fowl pox viruses }\end{array}$ & $\begin{array}{l}\text { - Produce strong innate } \\
\text { inflammatory immune response }\end{array}$ & $\begin{array}{l}\text {-Sensitivity to preexisted } \\
\text { immunity against vector }\end{array}$ & $\begin{array}{l}\text { (Dunn et al. } \\
\text { 2019) }\end{array}$ \\
\hline Virus like particles & -Genomeless VLPs are used & $\begin{array}{l}\text { - Safer } \\
\text { - Produce robust immune } \\
\text { responses }\end{array}$ & $\begin{array}{l}\text { - Difficult massive } \\
\text { vaccine production }\end{array}$ & $\begin{array}{l}\text { (Bello et al. } \\
\text { 2018) }\end{array}$ \\
\hline $\begin{array}{l}\text { Reverse genetic } \\
\text { based vaccines }\end{array}$ & $\begin{array}{l}\text {-Recovery from cDNA } \\
\text { - Modified cleavage site } \\
\text { (polybasic to monobasic) }\end{array}$ & $\begin{array}{l}\text {-Produce stable vaccines } \\
\text { - Differentiate virulent from } \\
\text { avirulent strain }\end{array}$ & -High cost & $\begin{array}{l}\text { (Bello et al. } \\
\text { 2020) }\end{array}$ \\
\hline Oral edible Vaccines & $\begin{array}{l}\text {-Agrobacterium mediated } \\
\text { transformation of gene } \mathrm{F} \text { and } \mathrm{HN} \\
\text { into plants }\end{array}$ & $\begin{array}{l}\text { - Higher expression } \\
\text { - Safer } \\
\text { - Efficient and effective }\end{array}$ & $\begin{array}{l}\text { - Hypersensitive } \\
\text { responses } \\
\text { - Need regular } \\
\text { monitoring }\end{array}$ & $\begin{array}{l}\text { (Shahid et al. } \\
\text { 2020) }\end{array}$ \\
\hline
\end{tabular}

\section{Immune response against infection and vaccination}

The key goal of any vaccine against NDV is to provide sterilizing immunity, protecting all bird species from a specific disease. The target areas of NDV are the epithelial cells of respiratory system and may spread to other essential tissues based on the pathogenicity of virus, increasing the level of mortality. The incubation period of vaccine for the onset of clinical disease is from 3 to 6 days, followed by the induction of active immunity (humoral, mucosal and cell mediated). Rather, innate immunity (interferon system) provides the first line defense against virus by inhibiting its replication to limit the spread of virus within the host. Various in vitro studies have shown that NDV induces the expression of innate immunity genes, like IFN-a, IFN-b, IFN-c and pro-inflammatory cytokines 6 and 1 . This was also verified by in vivo studies with an addition of regulation of chemokine genes. NDV antagonizes IFN response and host tropism qualities, as demonstrated by in vitro studies. There is a lot of progress and development of avian immunology but precise role of cellular immunity against NDV has not been studied yet. Antibodies (humoral response) have been detected approximately six days after the infection or vaccination with live virus. This method of producing antibodies by the use of vaccination is considered as an essential method for the protection against NDV by preventing viral spread. According to previous studies, use of inactivated vaccines or mesogenic strains via ocular and nasal routes results in the highest antibody titres 6-10 days after vaccination. However, preliminary measures should be considered in day-old chicks rather than vaccination because it proves to be ineffective due to MDA. The efficacy of live vaccination in young birds was also affected by high level of MDA, which caused delay in immune response, resultantly about $55 \%$ of birds remained unprotected. Application of live vaccine added the advantage of inducing humoral and cellular immunity, along with mucosal immunity, which plays an important role in the protection against ND. The production of antibodies can be detected by hemagglutination test, ELISA and various other methods but does not necessarily relate to the level of virus transmission. Therefore, further research is needed for improved understanding of immune response against NDV in avian species.

\section{Future Prospects}

Much research work has so far been done on NDV vaccines and the trends are likely to be followed in future. The government should prioritize the protection of livestock and agriculture sectors in the country by following rules and regulations of biosecurity. Vaccine technology should be upgraded and more new vaccination techniques must be introduced in near future. New strategies, expansion of laboratories, regular training and proper expertise would help in meeting the basic vaccine demands. Private sectors must also invest for research and development of vaccines at large scale for mass administration.

\section{REFERENCES}

Abdisa T and Tagesu T, 2017. Review on Newcastle disease of poultry and its public health importance. Journal of Veterinary Science and Technology 8: 3. DOI: 10.4172/2157-7579.1000441.

Abdolmaleki M, et al., 2018. Effects of Newcastle disease virus infection on chicken intestinal intraepithelial natural killer cells. Frontiers in Immunology 9: 1386. 
Alexander D, 200o. Newcastle disease and other avian paramyxoviruses. Revue Scientifique et TechniqueOffice International des Epizooties 19: 443-455.

Ashraf A and Shah M, 2014. Newcastle disease: Present status and future challenges for developing countries. African Journal of Microbiology Research 8: 411-416.

Ayala AJ, et al., 2016. Presence of vaccine-derived Newcastle disease viruses in wild birds. PLoS One 11: eo162484.

Baron MD, et al., 2018. Recent advances in viral vectors in veterinary vaccinology. Current Opinion in Virology 29: 1-7.

Bello MB, et al., 2020. Development of an effective and stable genotype-matched live attenuated Newcastle disease virus vaccine based on a novel naturally recombinant Malaysian isolate using reverse genetics. Vaccines 8: 270.

Bello MB, et al., 2018. Diagnostic and vaccination approaches for Newcastle disease virus in poultry: The current and emerging perspectives. BioMed Research International 5: 7278459. doi: 10.1155/2018/7278459.

Bensink Z and Spradbrow P, 1999. Newcastle disease virus strain I2-a prospective thermostable vaccine for use in developing countries. Veterinary Microbiology 68: 131139.

Berinstein A, et al., 2005. Mucosal and systemic immunization elicited by Newcastle disease virus (NDV) transgenic plants as antigens. Vaccine 23: 55835589.

Byarugaba DK, et al., 2014. High pathogenicity and low genetic evolution of avian paramyxovirus type I (Newcastle disease virus) isolated from live bird markets in Uganda. Virology Journal 11: 1-13.

Chen X, et al., 2020. Identification of Newcastle disease virus P-gene editing using next-generation sequencing. Journal of Veterinary Medical Science 82: 1231-1235.

Choi KS, et al., 2013. Preparation and diagnostic utility of a hemagglutination inhibition test antigen derived from the baculovirus-expressed hemagglutininneuraminidase protein gene of Newcastle disease virus. Journal of Veterinary Science 14: 291-297.

Commission IOOEBS and IOOEI Committee, 2008. Manual of Diagnostic Tests and Vaccines for Terrestrial Animals: mammals, birds and bees. Office International des Epizooties, Paris, France.

Conzelmann K, 2004. Reverse genetics of mononegavirales. Biology of negative strand RNA viruses. The Power of Reverse Genetics pp: 1-41.

Deurenberg RH, et al., 2017. Application of next generation sequencing in clinical microbiology and infection prevention. Journal of Biotechnology 243: 1624.

Dimitrov KM, et al., 2017. Newcastle disease vaccines-A solved problem or a continuous challenge? Veterinary Microbiology 206: 126-136.

Dunn JR, et al., 2019. Evaluation of protective efficacy when combining Turkey Herpesvirus-vector vaccines. Avian Diseases 63: 75-83.

Fauquet $C$ and Fargette D, 2005. International Committee on Taxonomy of Viruses and the 3,142 unassigned species. Virology Journal 2: 1-10.

Firouzamandi M, et al., 2016. Preparation, characterization, and in ovo vaccination of dextranspermine nanoparticle DNA vaccine coexpressing the fusion and hemagglutinin genes against Newcastle disease. International Journal of Nanomedicine 11: 259.

Ganar, et al., 2014. Newcastle disease virus: Current status and our understanding. Virus Research 184: 71-81.

Ge J, et al., 2016. Construction of recombinant baculovirus vaccines for Newcastle disease virus and an assessment of their immunogenicity. Journal of Biotechnology 231: 201-211.

Ghaffar A, et al., 2016. Expression of hemagglutininneuraminidase and fusion epitopes of Newcastle Disease Virus in transgenic tobacco. Electronic Journal of Biotechnology 19: 38-43.

He Y, et al., 2018. Whole-genome sequencing of genotype VI Newcastle disease viruses from formalin-fixed paraffin-embedded tissues from wild pigeons reveals continuous evolution and previously unrecognized genetic diversity in the US. Virology Journal 15: 1-11.

Kammon A, et al., 2015. Characterization of Avian Influenza and Newcastle disease viruses from poultry in Libya. Avian Diseases 59: 422-430.

Kapczynsk DR, et al., 2013. Immune responses of poultry to Newcastle disease virus. Developmental and Comparative Immunology 41: 447-453.

Khan TA, et al., 2010. Phylogenetic and biological characterization of Newcastle disease virus isolates from Pakistan. Journal of Clinical Microbiology 48: 1892-1894.

Khulape SA, et al., 2019. Evaluation of a fusion gene-based DNA prime-protein boost vaccination strategy against Newcastle disease virus. Tropical Animal Health and Production 51: 2529-2538.

$\mathrm{Kim} \mathrm{SH}$, et al., 2013. Newcastle disease virus fusion protein is the major contributor to protective immunity of genotype-matched vaccine. PloS One 8(8): e74022.

Kim SH and Samal SK, 2018. Reverse genetics for Newcastle disease virus as a vaccine vector. Current Protocols in Microbiology 48: 18.5.1- 18.5.12.

Kurup VM and Thomas J, 2020. Edible vaccines: Promises and challenges. Molecular Biotechnology 62: 79-90.

Laere E, et al., 2016. Plant-based vaccines: Production and challenges. Journal of Botany. Article ID 4928637, 11 pages, 2016.

Lamb RA and Jardetzky TS, 2007. Structural basis of viral invasion: lessons from paramyxovirus F. Current Opinion in Structural Biology 17: 427-436.

Liu F, et al., 2012. Virus-like particles: Potential veterinary vaccine immunogens. Research in Veterinary Science 93: 553-559.

Lung O, et al., 2012. Electronic microarray assays for Avian Influenza and Newcastle disease virus. Journal of Virological Methods 185: 244-253.

Luo B, et al., 2018. A novel immunosensor based on excessively tilted fiber grating coated with gold nanospheres improves the detection limit of 
Newcastle disease virus. Biosensors and Bioelectronics 100: 169-175.

MacLachlan N and E Dubovi, 2017. Paramyxoviridae and pneumoviridae. Fenner's Veterinary Virology. Elsevier, New York, NY, USA, pp: 327-356.

Marks et al., 2014. Targeted survey of Newcastle disease virus in backyard poultry flocks located in wintering site for migratory birds from Southern Brazil. Preventive Veterinary Medicine 116: 197-202.

Mauriz E, 2020. Recent progress in plasmonic biosensing schemes for virus detection. Sensors 20: 4745 .

Mayers et al., 2017. The role of vaccination in risk mitigation and control of Newcastle disease in poultry. Vaccine 35: 5974-5980.

Meng et al., 2016. Evolution of Newcastle disease virus quasispecies diversity and enhanced virulence after passage through chicken air sacs. Journal of Virology 90: 2052-2063.

Mielcarek et al., 2006. Live attenuated B. pertussis as a single-dose nasal vaccine against whooping cough. PLoS Pathogens 2: e65.

Miller et al., 2010. Newcastle disease: Evolution of genotypes and the related diagnostic challenges. Infection, Genetics and Evolution 10: 26-35.

OIE, 2017. Infection with Newcastle disease virus. Terres Animal Health Code 10: 1.

Pham et al., 2005. Loop-mediated isothermal amplification for rapid detection of Newcastle disease virus. Journal of Clinical Microbiology 43: 1646-165o.

Qiu et al., 2011. Entire genome sequence analysis of genotype IX Newcastle disease viruses reveals their early-genotype phylogenetic position and recentgenotype genome size. Virology Journal 8: 1-11.

Renu S and GJ Renukaradhya, 2020. Chitosan nanoparticle based mucosal vaccines delivered against infectious diseases of poultry and pigs. Frontiers in Bioengineering and Biotechnology 8: 1-16.

Seal et al., 1995. Characterization of Newcastle disease virus isolates by reverse transcription PCR coupled to direct nucleotide sequencing and development of sequence database for pathotype prediction and molecular epidemiological analysis. Journal of Clinical Microbiology 33: 2624-2630.

Shahid et al., 2020. Early stage development of a Newcastle disease vaccine candidate in corn. Frontiers in Veterinary Science 7: 1-12.

Shahzad et al., 2015. Immuno-pathologic effects of oral administration of chlorpyrifos in broiler chicks. Journal of Immunotoxicology 12: 16-23.
Shi et al., 2015. Development of SPR biosensor for simultaneous detection of multiplex respiratory viruses. Bio-Medical Materials and Engineering 26(s1): S2207-S2216.

Siddiqui et al., 2014. Role of natural products in drug discovery process. International Journal of Drug Development and Research 6(2): 172-204.

Steward, et al., 1993. RNA editing in Newcastle disease virus. Journal of General Virology 74: 2539-2547.

Sultankulova et al., 2017. New oligonucleotide microarray for rapid diagnosis of avian viral diseases. Virology Journal 14: 1-11.

Thomazelli et al., 2012. Molecular surveillance of the Newcastle disease virus in domestic and wild birds on the North Eastern Coast and Amazon biome of Brazil. Brazilian Journal of Poultry Science 14: 01-07.

Tlaxca et al., 2015. Live attenuated and inactivated viral vaccine formulation and nasal delivery: Potential and challenges. Advanced Drug Delivery Reviews 93: 5678.

Wang et al., 2001. Rapid detection and differentiation of Newcastle disease virus isolates by a triple one-step RT-PCR. The Onderstepoort Journal of Veterinary Research 68: 131-4.

Xiao et al., 2019. Development of oligonucleotide microarray for accurate and simultaneous detection of avian respiratory viral diseases. BMC Veterinary Research 15: 1-11.

Yusoff $\mathrm{K}$ and WS Tan, 2001. Newcastle disease virus: Macromolecules and opportunities. Avian Pathology 30: $439-455$.

Zhai et al., 2011. Enhancement of humoral immune responses to inactivated Newcastle disease and Avian Influenza vaccines by oral administration of ginseng stem-and-leaf saponins in chickens. Poultry Science 90: 1955-1959.

Zhang et al., 2020. Development and application of a triplex real-time PCR assay for simultaneous detection of avian influenza virus, Newcastle disease virus, and duck Tembusu virus. BMC Veterinary Research 16: 112.

Zhao et al., 2017. Immune effect of Newcastle disease virus DNA vaccine with $\mathrm{C}_{3} \mathrm{~d}$ as a molecular adjuvant. Journal of Microbiology and Biotechnology 27: 206o2069.

Zhao et al., 2018. Engineered recombinant protein products of the avian paramyxovirus type-1 nucleocapsid and phosphoprotein genes for serological diagnosis. Virology Journal 15: 1-12. 